\title{
Scottish Dragon Finder evaluation
}

\author{
V. Larcombe \& J. Stead \\ Froglife, 1 Loxley, Werrington, Peterborough PE4 5BW \\ E-mail: james.stead@froglife.org
}

\section{BACKGROUND}

Froglife is a national wildlife charity concerned with the conservation of the U.K.'s amphibian and reptile species and their associated habitats. Froglife's vision is a world in which reptile and amphibian populations are flourishing as part of healthy ecosystems.

Froglife's Scottish Dragon Finder project was a 4.5 year project that began in 2014. It was supported by the Heritage Lottery Fund and brought together practical conservation, interactive educational activities and data collection throughout Scotland to help conserve native reptiles and amphibians. Scottish Dragon Finder is now finished and here we describe the activities undertaken in the project, and some of its achievements.

\section{SCOTTISH DRAGON FINDER ACTIVITIES}

The project had many different approaches to engaging the public, with diverse activities developed to interact with a wide-ranging audience.

\section{Dragon Tails}

Dragon Tails were interactive educational sessions aimed at children. They were split into education workshops for primary school pupils and drama workshops for youth groups. School sessions, linked to the Curriculum for Excellence, taught primary school children skills in Science, Maths and English whilst introducing native amphibian and reptile species (Fig. 1). Drama workshops worked with youth groups across Scotland, where children were taught an amphibian and reptile-themed play, which they performed to their families and friends after spending time practising and learning about how native species look and move. The Dragon Tails team has engaged over 2,600 people through its activities, visiting 51 schools and 20 youth groups.

\section{Dragons on the Move}

The Dragons on the Move activity travelled across Scotland bringing free wildlife experiences to a diverse range of people and enthusing them about our native species. The activity offered educational amphibian crafts, walks to spot amphibian and reptile species and Froglife stalls to answer questions and provide advice. Over 29,000 people attended Dragons on the Move activities across Scotland at 72 events.

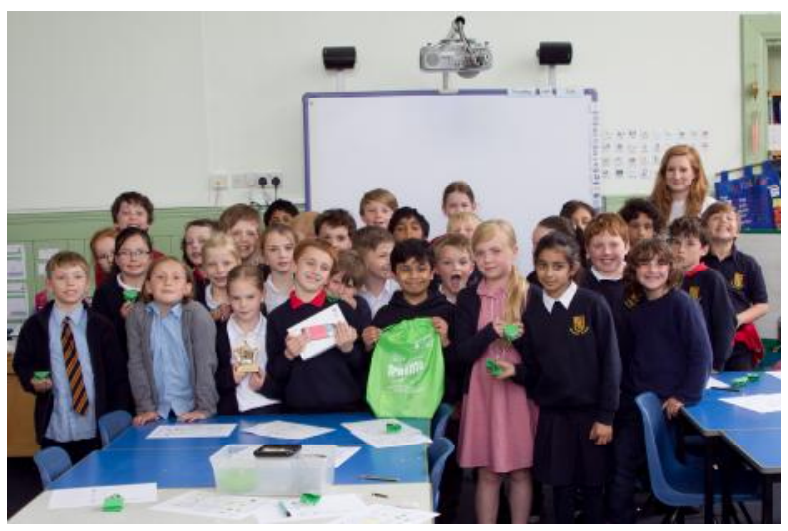

Fig. 1. Dragon Tails at Sciennes Primary School, City of Edinburgh. Dragon Tails are interactive educational sessions for primary school pupils, teaching skills in science, maths and English whilst introducing native amphibian and reptile species.

\section{Dragons in your Garden}

The Scottish Dragon Finder team visited therapeutic gardens all over Scotland (Fig. 2). It delivered workshops teaching gardeners with mental health issues or physical or learning disabilities about native amphibians and reptiles, and showed them how to garden in a wildlife-friendly way. This was followed by a model wildlife garden activity, where workshop attendees created their own table-top wildlife garden from a blank slate to give them ideas for the future. Finally we headed out to the garden with the group creating wildlife friendly features including hibernacula, bog gardens, ponds or raised ponds. In addition, Scottish Dragon Finder also included a number of "train the trainer" workshops to share skills, and teach groups of garden leaders how to run wildlife gardening sessions with their own teams. The team engaged over 530 garden users and visited 36 therapeutic and community gardens.

\section{Dragons on the Hills}

Not enough is known about the distribution of amphibians and reptiles in remote areas of Scotland, as these areas can be hard to access on a regular basis or unfeasible for staff to reach for survey and monitoring purposes. However, hill-walking and other outdoor pursuits are popular pastimes in 
Scotland, with many people heading to the outdoors in their free time. Dragons on the Hills aimed to enthuse and educate people who regularly visit Scotland's wild areas, teaching them how to spot and identify native amphibians and reptiles and submit their sighting using Froglife's free Dragon Finder app. Over 200 outdoor enthusiasts joined the Dragons on the Hills sessions on the ten walks we held, and all participants were introduced to the Dragon Finder app.

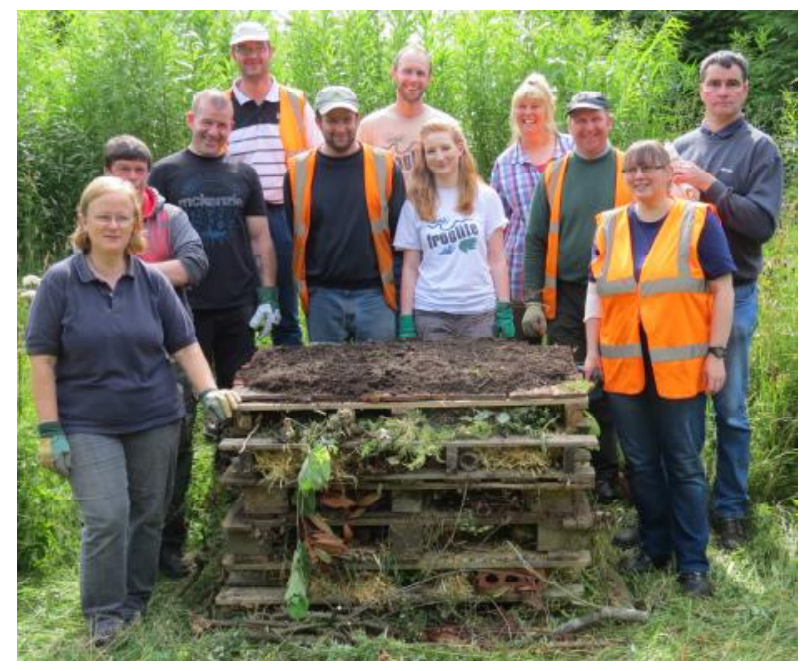

Fig. 2. Dragons in your Garden at Hansel Alliance Group, South Ayrshire. These workshops teach gardeners with mental health issues, or physical or learning disabilities about native amphibians and reptiles, and show them how to garden in a wildlife-friendly way.

\section{Dragon Finder app}

The Dragon Finder smartphone app allows anyone with an Android/iPhone device to learn more about the U.K.'s amphibian and reptile species: their ecology, identification features, calls and more. The app can answer questions to aid their identification and by submitting sightings they are building a clearer picture of the distribution of native and nonnative amphibian and reptile species throughout Scotland and the rest of the U.K. Photos of sightings can be submitted which can be extremely useful if these are of diseased animals. The app also includes a species database offering pictures, calls and information on the basic ecology of native and nonnative species.

\section{Habitat creation/restoration}

Scottish Dragon Finder aimed to create and restore reptile and amphibian habitats across Scotland, which included creating new ponds, restoring old ponds that had developed problems and creating reptile habitats suitable for basking. The project created 52 new ponds and restored 16 ponds across 25 locations, alongside terrestrial improvements.

Evanton Wood near Dingwall, Highlands was one of the early Scottish Dragon Finder project sites. It is owned by the Evanton Wood Community Company (http://www.evantonwood.com/index.asp) who were motivated to establish ponds within their community woodland site. The clay soil on site allowed for ponds to be created with artificial liners and, with the help of hired contractors, three ponds were created with different shapes, sizes and depths - the largest measuring $26 \mathrm{~m} \times 19 \mathrm{~m}$. A fourth pond was created with local volunteers which resulted in a network of ponds offering varied habitats for amphibians and associated pond wildlife.

Strathnairn Community Woodland near Inverness, Highland, also locally owned and managed, was completed at the end of 2016 (http://www.strathnairn.org.uk/strathnairncommu nitywoodlands.asp). A network of ponds was created with a timber boardwalk to allow access for visitors (Fig. 3). Volunteers helped to create hibernacula nearby for overwintering reptiles and amphibians. The success of the ponds allowed the Scottish Dragon Finder team to run an outdoor school session with Farr Primary School, followed on another date by an evening amphibian survey training event, which attracted many local people.

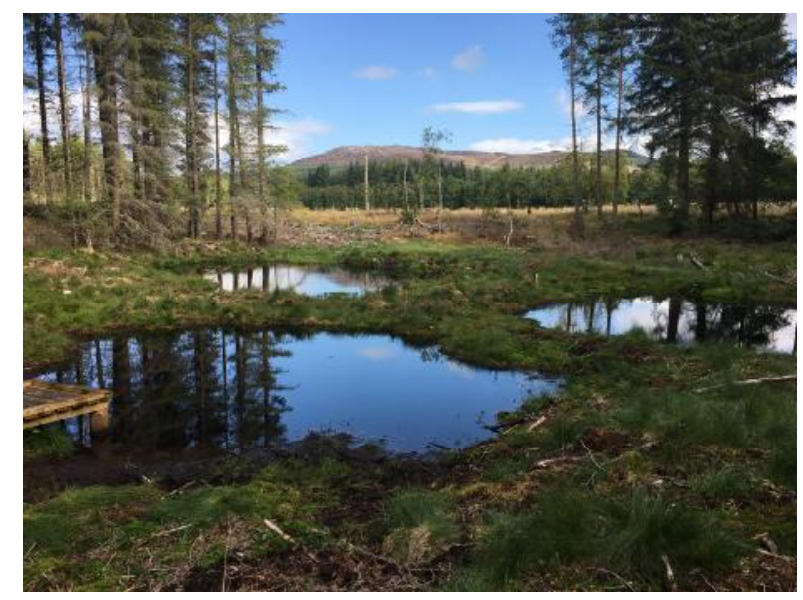

Fig. 3. Three ponds created at Strathnairn Community Woodlands near Inverness, Highland, for amphibians and pond wildlife as part of the Scottish Dragon Finder project.

\section{Tay View Community Garden}

(https://en-b.facebook.com/tayviewcommunitygarden/) was one of the final sites of Scottish Dragon Finder. Set in the heart of Dundee on the site of a nursing home, Froglife worked with Dundee City Council to create a new lined pond with a pond-dipping platform for educational sessions. The new pond is a welcome feature within the developing garden site for local users and for the many people passing through the gardens, which are bordered by residential properties, a medical centre, and a school.

\section{Training and volunteering}

To ensure the longevity of the habitat projects, a programme of training and volunteer days was setup. These allowed local people to learn more about the habitats around them and a chance to get outdoors and be active. They also learned skills in 
amphibian and reptile surveying and identification, and skills in pond creation and management. Forty training and volunteer days were held throughout Scotland, with over 440 local people attending and learning new skills.

\section{Traineeships}

Two salaried 18-month traineeships were offered as part of the project to give those looking to start their career in nature conservation the chance to learn skills in public engagement and practical habitat work. We are delighted that both trainees have found employment since completing their traineeships; one has gone on to do a Ph.D. in conservation and the other now works for Buglife.

\section{And finally...}

Scottish Dragon Finder has worked across 31 of the 32 council areas within Scotland, with Shetland being the only council area we were not able to visit. During this time we have had some great feedback from those involved!

"I learned all about what a newt is and all about amphibians and reptiles that live in Scotland." Louise age 10 - Dragon Tails

"This was a good experience as it's something I never thought to do."

- Highlands - Amphibian training session attendee "Gained knowledge about frogs, toads, slow-worms and snakes. The garden designing exercise was excellent - fun, creative and thought provoking."

- Falkirk - Dragons in your Garden attendee

\section{ACKNOWLEDGEMENTS}

A big thanks to Heritage Lottery Fund and all those who have funded and supported Scottish Dragon Finder - a full list can be seen at: www.froglife.org/dragonfinder/scotland/funders/ 